\title{
Pengaruh Personal Branding Felicya Angelista di Instagram terhadap Loyalitas Pelanggan Produk Scarlett Whitening
}

\author{
Leticia, Farid Rusdi \\ leticia.915170184@stu.untar.ac.id,farid@fikom.untar.ac.id \\ Fakultas Ilmu Komunikasi Universitas Tarumanagara
}

\begin{abstract}
With the rapid use of the internet in Indonesia which is dominated by the use of social media, various social media applications have emerged that can help everyone to get and share information easily and quickly. Social media is currently also being used as a new online business platform, one of which is Instagram social media. Social media is not only used as a photo and video sharing application, but Instagram is currently used as a promotional tool in terms of doing business and building Personal Branding online. Many people are currently building their Personal Branding through Instagram such as one beautiful Indonesian artist named Felicya Angelista who currently has 16.6 million Instagram followers. Felicya Angelista also takes advantage of Instagram as a new online business platform, namely Scarlett Whitening. Currently Scarlett Whitening is always being promoted by Felicya Angelista through her Instagram account so that Felicya Angelista's Instagram followers know about Scarlett Whitening and end up in loyalty. Researchers have a goal to find out whether there is an effect of Felicya Angelista's Personal Branding on Instagram on customer loyalty for Scarlett Whitening products. This research was conducted using a quantitative approach and simple linear regression analysis. The sampling technique used was non-probability with a purposive sampling approach, as many as 100 respondents from Instagram Scarlett Whitening. The technique used for data collection is a questionnaire. Test requirements analysis using validity, reliability, and normality tests. Likewise, the data validity technique used is the t test, simple regression analysis, correlation analysis, and analysis of the coefficient of determination. With the results of the t test, it shows that the $t$ value is 2.770>1.984 t table which shows that there is an influence from Felicya Angelista's Personal Branding via Instagram on customer loyalty for Scarlett Whitening products.
\end{abstract}

Keywords: customer loyalty, instagram, personal branding, social media

\begin{abstract}
Abstrak
Pesatnya penggunaan internet di Indonesia yang didominasi oleh penggunaan media sosial, maka muncul berbagai macam aplikasi media sosial yang dapat membantu semua orang untuk mendapatkan dan berbagi informasi dengan mudah dan cepat. Media sosial saat ini juga digunakan sebagai wadah bisnis online yang baru, salah satunya adalah media sosial Instagram. Media sosial ini tidak hanya digunakan sebagai aplikasi berbagi foto dan video saja, tetapi Instagram saat ini digunakan sebagai alat promosi dalam hal berbisnis dan membangun Personal Branding secara online. Banyak kalangan yang saat ini membangun Personal Brandingnya melalui Instagram seperti salah satu artis cantik Indonesia bernama Felicya Angelista yang saat ini memiliki pengikut Instagram sebanyak 16,6 juta. Felicya Angelista juga turut memanfaatkan Instagram sebagai sarana bisnis onlinenya yang baru yaitu Scarlett Whitening. Saat ini Scarlett Whitening selalu dipromosikan oleh Felicya Angelista melalui akun Instagramnya agar para pengikut Instagram Felicya Angelista mengetahui keberadaan Scarlett Whitening dan berakhir pada loyalitas. Peneliti memiliki tujuan untuk mengetahui apakah ada perngaruh Personal Branding Felicya Angelista di Instagram terhadap loyalitas pelanggan produk Scarlett Whitening. Penelitian yang
\end{abstract}


dilakukan ini menggunakan pendekatan kuantitatif dan analisis regresi linear sederhana. Teknik penarikan sampel yang digunakan adalah non-probability dengan pendekatan purposive sampling, responden sebanyak 100 orang dari Instagram Scarlett Whitening. Teknik yang digunakan untuk pengumpulan data yaitu menggunakan kuesioner. Uji persyaratan analisis menggunakan uji validitas, reliabilitas, dan normalitas. Begitu juga dengan teknik keabsahan data yang digunakan adalah uji t, analisis regresi sederhana, analisis korelasi, dan analisis koefisien determinasi. Dengan hasil uji t menunjukkan nilai $t$ hitung adalah $2.770>1,984 \mathrm{t}$ table yang menunjukkan bahwa adanya pengaruh dari Personal Branding Felicya Angelista melalui Instagram terhadap loyalitas pelanggan produk Scarlett Whitening.

Kata Kunci: instagram, loyalitas pelanggan, media sosial, personal branding

\section{Pendahuluan}

Dalam era globalisasi seperti saat ini internet sangat dibutuhkan dalam setiap aktivitas kehidupan masyarakat baik untuk mencari informasi, berkomunikasi jarak jauh dan bahkan melalukan bisnis online. Indonesia saat ini juga merupakan salah satu negara pengakses internet tertinggi di dunia. Peningkatan penggunaan internet di Indonesia diakibatkan oleh masyarakat Indonesia yang aktif mengakses dan menggunakan media sosial. McGraw Hill Dictionary mengatakan bahwa media sosial sendiri merupakan sarana yang digunakan oleh banyak orang untuk berinteraksi satu sama lain dengan cara menciptakan, berbagi, serta bertukar informasi dan gagasan dalam sebuah jaringan dan komunitas virtual. Ini adalah bentuk konkret komunikasi.

Komunikasi sendiri merupakan kebutuhan bagi manusia, baik komunikasi verbal maupun non-verbal. Dalam setiap bidang tak terkecuali bisnis, komunikasi menjadi salah satu hal yang signifikan pengaruhnya.

Media sosial sendiri dapat dikatakan sebagai sarana komunikasi yang efektif dan memiliki harga yang terjangkau. Untuk menciptakan proses komunikasi yang efektif, pembisnis juga harus memahami strategi komunikasi pemasaran baik secara online atau offline. Komunikasi pemasaran yang dilakukan secara online juga membutuhkan bantuan media sosial seperti Youtube, WhatsApp, Instagram dan banyak media sosial lainnya. Guna memanfaatkan media sosial sebagai perantara berkomunikasi agar perusahaan atau pembisnis dapat menjangkau masyarakat secara luas dan mudah.

Banyaknya berbagai macam media sosial bermunculan dan berlomba menjadi pilihan masyarakat, misalnya dengan memberi kemudhan akses, konten yang menarik dan ffitur lain yang dapat dipergunakan untuk ajang promosi bisnis yang kita miliki. Instagram misalnya telah menajdi sebuah aplikasi yang sering dan aktif digunakan oleh masyarakat saat ini untuk berbagi foto, video, informasi dan menjadi sarana bisnis online yang baru. Instagram juga memiliki beberapa fitur-fitur menarik seperti like dan comment, explore, IGTV, Instagram story dan Instagram bisnis. Instagram sendiri membuka peluang baru untuk para pengguna melakukan bisnis online, dengan cara mengalihkan akun yang biasa menjadi akun bisnis. Instagram sendiri membantu penjual dan pembeli untuk berkomunikasi dengan sangat mudah dan cepat.

Dengan kehadiran Instagram, seseorag dapat melihat kenaikan dan penurunan dari berapa viewers yang melihat akun bisnis, auto replay, dan siapa saja yang mengikuti sebuah akun. Instagram juga tidak membatasi produk atau jasa yang ingin 
dijadikan bisnis seperti menjual makanan, pakaian, jasa properti, produk kecantikan dan lain-lain. Instagram juga tidak memandang siapa yang menjual dan dari usia berapa yang menjual, maka dari itu para pengguna dapat dengan bebas melalukan jual beli online melalui Instagram.

Salah satu artis Indonesia, Felicya Angelista, ikut memanfaatkan Instagram untuk melakukan bisnisnya di bidang produk kecantikan. Felicya Angelista kemudian memutuskan untuk terjun dalam dunia bisnis kecantikan yang bernama Scarlett Whitening (Wibi, 2019). Felicya Angelista juga memanfaatkan Instagram pribadinya sebagai sarana untuk membangun personal branding dan sebagai sarana promosi online untuk bisnisnya yaitu Scarlett Whitening.

Felicya Angelista membangun personal brand miliknya dengan cara mengomunikasikan kegunaan produk, manfaat dan hasil yang di berikan oleh produk Scralett Whitening. Komunikasi yang digunakan Felicya sendiri merupakan komunikasi secara verbal dan komunikasi secara non-verbal yang dapat dilihat dari setiap postingan yang Felicya bagikan di Instagramnya, agar para pengikutnya selalu dapat melihat setiap aktivitas, keseharian Felicya dan bahkan mengenal produk Scarlett Whitening.

Personal branding sendiri diartikan sebagai proses dasar menciptakan persepsi masyarakat kepada banyak aspek yang dimiliki seseorang, seperti kepribadian, kemampuan, nilai-nilai yang akhirnya mampu memberikan persepsi positif dari masyarakat (Haroen, 2014). Namun berbeda dengan McNally dan Speak yang mengartikan personal branding sebagai persepsi yang selalu diingat oleh orang lain dan memiliki tujuan akhir agar publik punya pandangan positif terhadapnya sehingga dapat berlanjut kepada kepercayaan dan loyalitas (Khairul, 2019).

Loyalitas konsumen sendiri sebagai proses menunjukkan adanya komitmen pelanggan terhadap satu merek yang dapat dilihat dari cara pembelian berulang dalam jangka panjang (Nurwidayat, 2015).

\section{Metode Penelitian}

Dalam penelitian ini, peneliti berusaha menganalisis secara komprehensif personal branding Felicya Angelista terhadap loyalitas pelanggan produk Scarlett Whitening menggunakan pendekatan kuantitatif. etode kuantitatif merupakan metode penelitian berdasarkan filsafat positivisme dan digunakan untuk meneliti populasi atau sample tertentu dan dilakukan secara random atau acak (Yudhiantika, 2019). Berdasarkan judul dan permasalahan yang diteliti, penelitian memiliki 2 variabel dalam penelitian yaitu variabel $\mathrm{X}$ dan $\mathrm{Y}$ untuk menunjukkan hubungan diantara variabel dan pengujian yang digunakan.

Penelitian ini juga menggunakan pengumpulan data dengan kuisioner atau angket. Kuesioner diartikan oleh Sugiyono sebagai teknik pengumpulan data yang dilakukan dengan cara memberi pertanyaan tertulis kepada responden untuk dijawab (Josephine dan Harjanti, 2017). Populasi dan sampel yang diambil peneliti berasal dari Instagram Scarlett Whitening sebanyak 100 responden. Peneliti memberikan pertanya kepada responden untuk mengetahui apakah ada pengaruh personal branding dari Felicya Angelista terhadap loyalitas pelanggan produk Scarlett Whitening. Populasi sendiri diartikan oleh Sugiyono sebagai objek atau subjek yang memiliki kualitas dan karakteristik sesuai yang telah ditentukan oleh peneliti dan kemudian ditarik kesimpulannya untuk dipelajari (Wahyuningtias et al., 2014). Begitu juga dengan sempel menurut Sekaran merupakan suatu kelompok atau 
sebagian dari populasi. Peneliti juga mampu menarik kesimpulan dengan mempelajari sampel (Waspodo et al., 2013).

\section{Hasil Penemuan dan Diskusi}

Berdasarkan hasil kuesioner yang disebarkan kepada followers Instagram Scarlett Whitening, penulis memperoleh data karakteristik responden yang terdiri dari jenis kelamin responden, umur responden. Jumlah karakteristik responden berdasarkan jenis kelamin laki-laki sebanyak 28 orang $(28 \%)$ dan responden yang berjenis kelamin perempuan sebanyak 72 orang $(72 \%)$ hal ini menandakan bahwa responden di dominasi oleh perempuan. Kemudian, sebagian usia responden 17-25 tahun sebanyak 98 orang (98\%), usia responden 26-35 tahun sebanyak 2 orang (2\%), dan usia responden $>35$ tahun sebanyak $(0 \%)$ atau tidak ada. Hal ini menunjukkan bahwa dominasi umur followers Scarlett Whitening di Instagram berusia 17-25 tahun.

Tabel 1. Analisis Regresi Linear Sederhana

Coefficients $^{\mathrm{a}}$

\begin{tabular}{|c|c|c|c|c|c|}
\hline \multirow[t]{2}{*}{ Model } & \multicolumn{2}{|c|}{$\begin{array}{l}\text { Unstandardized } \\
\text { Coefficients }\end{array}$} & $\begin{array}{l}\text { Standardized } \\
\text { Coefficients }\end{array}$ & \multirow[t]{2}{*}{$\mathrm{t}$} & \multirow[t]{2}{*}{ Sig. } \\
\hline & B & Std. Error & Beta & & \\
\hline (Constant) & 11.594 & 10.002 & & .1 .159 & .249 \\
\hline \begin{tabular}{|ll}
1 & Personal \\
& Branding
\end{tabular} & .821 & .297 & .269 & 2.770 & .007 \\
\hline
\end{tabular}

a. Dependent Variable: Loyalitas Pelanggan

Sumber: Pengolahan Data SPSS 25

Pada tabel output di atas, diperoleh nilai a sebesar 11,594 dan koefisien b sebesar 0,821 yang dapat diinterpretasikan yaitu, a sebagai angka konstan dari unstandardized Coefficients. Dalam penelitian ini nilainya sebesar 11,594. Angka ini merupakan angka konstan yang mempunyai arti bahwa jika tidak ada Personal Branding (X) maka nilai Loyalitas Pelanggan (Y) adalah 0,821. Sedangkan b adalah koefisien regresi bernilai sebesar 0,821 . Koefisien regresi tersebut bernilai positif, artinya ada hubungan positif antara Personal Branding Felicya Angelista di Instagram terhadap loyalitas pelanggan Produk Scarlett Whitening.

Dari hasil penelitian tersebut diperoleh bahwa Personal Branding dalam memperkenalkan sebuah produk lebih signifikan hasilnya dibandingkan dengan branding yang dilakukan dari perusahaan atau organisasinya, seperti yang dilakukan oleh Felicya Angelista yang membangun personal brandingnya melalui Instagram dengan cara memposting setiap kegiatan dan aktifitasnya serta memberikan nilainilai yang positif dan membangun kepada publiknya sehingga publik dan pengikut di Instagramnya merasa percaya dan menilai Felicya dengan citra yang positif. Peneliti juga telah mendapatkan hasil dari 100 responden melalui Instagram Scarlett Whitening dan peneliti mendapatkan hasil bahwa personal branding Felicya Angelista memiliki pengaruh terhadap loyalitas pelanggan produk Scarlett Whitening.

Penelitian ini memiliki 20 pertanyaan dengan menggunakan uji validitas, uji reliabilitas, uji normalitas dan uji-t untuk mengetahui hasil akhir dari penelitian tersebut. Uji validitas dan uji realibilitas yang dilakukan oleh peneliti telah 
menunjukan hasil yang valid dan reliabel sehingga dapat dikatakan bahwa uji validitas dan reliabilitas memiliki nilai lebih besar dari yang telah ditentukan, lalu uji normalitas yang dilakukan oleh peneliti menghasilkan nilai yang normal karena nilai uji lebih besar dari nilai signifikan yang telah ditentukan. Uji - $\mathrm{t}$ yang di hasilkan dari penelitian ini juga menunjukan bahwa $t$ hitung lebih besar dari $t$ tabel dan terbukti memberikan pengaruh terhadap variabel.

\section{Simpulan}

Dari hasil penelitian yang telah dilakukan, peneliti menyimpulkan bahwa personal branding Felicya Angelista di Instagram memiliki pengaruh terhadap loyalitas pelanggan produk Scarlett Whitening. Hal ini dapat terjadi karena personal branding dari Felicya Angelista yang sudah dinilai positif oleh masyarakat dan melakukan promosi secara konsisten terhadap Scarlett Whitening.

Loyalitas dari pelanggan produk Scarlett Whitening juga dapat dilihat dari pembelian berulang oleh pelanggan produk Scarlett Whitening dalam hasil penelitian di atas. Felicya sendiri juga merupakan seorang perempuan muda yang cantik berkulit putih yang sangat menarik perhatian para wanita lainnya untuk memiliki kulit putih seperti Felicya Angelista. Hal tersebut mampu memberikan nilai tambah kepada Felicya dalam mempromosikan produk Scarlett Whitening. Begitu juga dengan usia yang di dominasi pada 17 sampai 25 tahun yang menadakan bahwa Followers Instagram dari Scarlett masih tergolong anak-anak muda.

Bagi penelitian selanjutnya, diharapkan dapat menambah faktor yang mempengaruhi Personal Branding serta loyalitas pelanggan dan memperluas faktorfaktor yang akan diteliti dan objek penelitian yang dipilih lebih umum agar topik penelitian lebih menarik dan diketahui oleh semua kalangan.

\section{Ucapan Terima Kasih}

Dengan segenap hati peneliti mengucapkan terima kasih yang sebesarbesarnya kepada semua pihak yang membantu terlaksananya penelitian ini hingga dapat dipublikasikan, khususnya kepada dosen dan rekan mahasiswa di Program Sarjana Ilmu Komunikasi Universitas Tarumanagara, serta seluruh responden yang telah bersedia untuk membantu peneliti dalam masa penelitian dan semua pihak yang sudah membantu, mendukung, dan berpartisipasi dalam pelaksanaan penelitian ini.

\section{Daftar Pustaka}

Josephine, A., \& Harjanti, D. (2017). Pengaruh Lingkungan Kerja Terhadap Kinerja Karyawan Pada Bagian Produksi Melalui Motivasi Kerja Sebagai Variabel Intervening Pada PT. Trio Corporate Plastic (Tricopla). Agora, 5(2).

Khairul, M. A., Zanganeh, J., \& Moghtaderi, B. (2019). The composition, recycling and utilisation of Bayer red mud. Resources, Conservation and Recycling, 141, 483-498.

Nurwidayat, A. (2015). Analisis Pengaruh Pelayanan Dan Keragaman Barang Terhadap Loyalitas Konsumen (Studi Pada Pasar Bunder Di Sragen). Skripsi, Universitas Muhammadiyah Surakarta. 
Wahyuningtias, D., Putranto, T. S., \& Kusdiana, R. N. (2014). Uji Kesukaan Hasil Jadi Kue Brownies Menggunakan Tepung Terigu Dan Tepung Gandum Utuh. Binus Business Review, 5(1), 57-65.

Waspodo, A. A., Handayani, N. C., \& Paramita, W. (2013). Pengaruh Kepuasan Kerja Dan Stres Kerja Terhadap Turnover Intention Pada Karyawan Pt. Unitex Dibogor. Jurnal Riset Manajemen Sains Indonesia, 4(1), 97-115.

Wibi, G. (14 November 2019). 9 Pencapaian Karier Felicya Angelista di Usia 25 Tahun. Retrieved from www.idntimes.com: https://www.idntimes.com/hype/entertainment/rani-48/9-pencapaian-karirfelicya-angelista-c1c2/9 .

Yudhiantika, S. (2019). Pengaruh Pemahaman Akuntansi Pajak Dan Penerapan EFiling Terhadap Kepatuhan Wajib Pajak (Survey Pada Kantor Pelayanan Pajak Pratama Bandung Cibeunying). Skripsi, Universitas Pasundan. 